\title{
Early high volume lung lavage for acute severe smoke inhalation injury in dogs
}

\author{
FACHUAN NIE, DONG SU, YING SHI, JINMEI CHEN, HAIHUI WANG, \\ WANXIANG QIN, SUXIA WANG and YAOHUA CHEN \\ Department of Pain Care and Nonvascular Intervention, The First Subordinate Hospital, \\ Third Military Medical University, Chongqing 400038, P.R. China
}

Received May 3, 2013; Accepted December 11, 2013

DOI: $10.3892 / \mathrm{mmr} .2013 .1877$

\begin{abstract}
The aim of the present study was to investigate the safety and short-term results of early high volume lung lavage in the treatment of acute severe smoke inhalation injuries in dogs. A high-volume normal saline complex solution lavage in the left lung was performed $1 \mathrm{~h}$ subsequent to bilateral pulmonary acute severe sawdust smoke inhalation injury in dogs. Lavage of the right lung was conducted following an interval of $30 \mathrm{~min}$ or $4 \mathrm{~h}$. The perfluorodecalin lavage was performed in dogs with unilateral pulmonary acute severe sawdust smoke inhalation injury. The present study identified that lavage with an interval of $4 \mathrm{~h}$ between two lungs was safer compared with a 30-min interval. Following lavage, the increase in the levels of free radical metabolites and inflammatory mediators in the lung homogenate was reduced. Acute severe smoke inhalation injury in one lung evidently caused a secondary injury to the other lung in the dogs. Perfluorodecalin lavage did not achieve the same effect in cleansing the lungs as the normal saline, but a greater comprehensive short-term outcome was obtained. These observations demonstrated that early high-volume lung lavage following severe smoke inhalation injury could relieve primary injuries and secondary local and general inflammatory reactions in dogs. An improved comprehensive short-term outcome was obtained in the perfluorodecalin-lavaged dogs.
\end{abstract}

\section{Introduction}

Inhalation injury immediately causes hypoxemia and mixed gas poisoning, followed by tracheobronchitis, pneumonia, pulmonary atelectasis, pulmonary embolism, pulmonary congestion and pulmonary edema due to direct injuries and secondary inflammatory reactions. These changes are the

Correspondence to: Dr Fachuan Nie, Department of Pain Care and Nonvascular Intervention, The First Subordinate Hospital, Third Military Medical University, Gaotanyan Road No. 30, Shapingba, Chongqing 400038, P.R. China

E-mail: fachuan_nie@sina.com

Key words: inhalation injury, lung lavage, pulmonary function, secondary inflammatory response, perfluorodecalin pathophysiological mechanism of respiratory failure. For a long time, the mortality rate of severe smoke inhalation injury patients has remained relatively high, and little improvement has been made in therapeutic strategies. One major reason is the failure to thoroughly and effectively cleanse the tracheal mucous membrane, which is injured and shed off, and remove the harmful extraneous matters remaining in the lungs; instead, following the development of pulmonary function damage, only some supporting treatments such as oxygen inhalation, sputum drainage and respiration controlling are administered $(1,2)$.

Theoretically, early lung lavage following inhalation injury could relieve the primary injury and secondary inflammatory reactions by eliminating a degree of the harmful dust, inflammatory exudates, cytokines and other secondary damage factors. By exhibiting a role similar to burn wound debridement, early lung lavage could extenuate the respiratory tract injury. The earlier it is administered, the greater the results achieved. Conversely, the early stage of inhalation injury is also the time of blood carbon monoxide emission (3). During the lung lavage period, patients under general hypoxia may suffer from a ventilation disorder and following lavage, they may exhibit lung water retention (4). These possibilities may result in patient mortality, and therefore decrease the likelihood of early lung lavage surgery being performed $(5,6)$.

Aiming at investigating a whole-lung lavage technique for general clinical application through animal experimentation, the present study evaluated the safety and short-term effects of the early high volume normal saline complex solution lung lavage for acute severe smoke inhalation injury in dogs. In addition, the present study aimed to discuss the mechanism of the effects from the aspects of changes in the systemic and local inflammatory mediators, pulmonary pathomorphology and pulmonary gas exchange.

\section{Materials and methods}

Animal preparation. Mongrel dogs were involved in the lung lavage experiments as the pathophysiological characteristics of their lungs resembles that of human beings. All the experiments were performed in accordance with the Chinese legislation on the protection of animals and the 1996 National Institutes of Health Guide for the Care and Use of Laboratory 
Animals. The experiments were performed on 38 hybrid male dogs (provided by the Animal Centre of the Third Military Medical University), weighing 11-15 kg. Subsequent to being observed for one week at the Laboratory Animal Centre of Third Military Medical University (Chongqing, China), the dogs, which were physically and behaviorally normal and eating normally, were used in the experiment.

Model construction of severe smoke inhalation injury in dogs

Models of bilateral pulmonary inhalation injury in dogs. Models of acute severe sawdust smoke inhalation injury were established in the traditional way as follows 75): A $1000 \mathrm{~W}$ electric stove was switched on until the temperature in the smoke generator reached $150^{\circ} \mathrm{C}$. Dry sawdust $(150 \mathrm{~g})$ was then placed into it and heated for $5 \mathrm{~min}$. Following that, the a Newport-900C ventilator (Newport Medical Instruments, Inc., Costa Mesa, CA, USA) was connected to ventilate $(320 \mathrm{ml} / \mathrm{min}, 18$ times $/ \mathrm{min})$. By adjusting the tube length, the smoke at the venthole was maintained at a temperature of $30-40^{\circ} \mathrm{C}$. At $5 \mathrm{~min}$ after ventilation, smoke was introduced to the dogs (anesthetized with $10 \mathrm{mg} / \mathrm{kg}$ ketamine hydrochloride and $0.3 \mathrm{mg}$ atropine sulfate; IM; both from Beijing Double-Crane Pharmaceutical Co., Ltd., Beijing, China) through the endotracheal tube (\#7.5; Tuoren Medical Instruments Co., Ltd., Beijing, China). Ventilation was switched to air for $3 \mathrm{~min}$ when the systolic arterial pressure was $<90 \mathrm{mmHg}$ or the heart rate was $<110 \mathrm{bpm}$. The smoke was delivered for a cumulative time of $5 \mathrm{~min}$.

Models of left pulmonary smoke inhalation injury in dogs. A two-lung ventilation was achieved by inserting a rigid slim polypropylene tube (inner diameter $3 \mathrm{~mm}$; Tuoren Medical Instruments Co., Ltd.), into the right bronchus of the anesthetized dogs; and inserting a normal F7.5 endotracheal tube to the left bronchus and then adjusting it by a bronchofiberscope (Olympus Medical Systems, Tokyo, Japan). Smoke was introduced to the left lung at a tidal volume (TV) of $200 \mathrm{ml}, 18$ times/min, for a cumulative time of $5 \mathrm{~min}$. During the smoke-ventilation in the left lung, oxygen-jet ventilation (Nanchang Kama Co., Ltd., Nanchang, China) of the right lung was performed at a pressure of $0.15 \mathrm{~kg} / \mathrm{cm}^{2}$ and a frequency of 10 times per min. Following the smoke delivery, the tubes were adjusted to the main trachea for spontaneous air breathing.

Bronchoalveolar lavage procedure. Lavage of the left lung: A slim rigid polypropylene tube ( $3 \mathrm{~mm}$ inner diameter) was inserted alongside the F7.5 tracheal tube to $\sim 1 \mathrm{~cm}$ above the carina. During the left-lung lavage, the dogs were placed in an $\sim 70^{\circ}$ left lateral position. The balloon of the main tracheal tube was released and pure oxygen was delivered into the two lungs through the slim tube by a jet ventilator $\left(0.15 \mathrm{~kg} / \mathrm{cm}^{2}\right.$ oxygen pressure, 30 times/min frequency). A bronchofiberscope was inserted through the main tracheal tube to $1.5 \mathrm{~cm}$ below the left lung carina. Normal saline complex solution $\left(50 \mathrm{ml}\right.$ at $37^{\circ} \mathrm{C}$ ) was introduced via the bronchofiberscope. Vacuum aspiration (Jiangsu Kangnuo Medical Instrument Co., Ltd., Changshu, China) was performed $30 \mathrm{sec}$ after thoracic massage. Following this, normal saline complex solution was infused (15-30 $\mathrm{ml}$ per time), to the extent that the lavage fluid did not overflow near the carina to a total lavage volume of $250 \mathrm{ml}$. Following the final delivery of the normal saline complex solution, vacuum aspiration was conducted to the extent that no lavage fluid was observed at the opening of the fourth-generation bronchus. The normal saline complex solution contained $900 \mathrm{ml}$ normal saline, $50 \mathrm{ml}$ distilled water and $50 \mathrm{ml} \mathrm{5 \%}$ sodium bicarbonate (330 osm/1, pH 7.8). Lavage of the right lung was conducted in the same manner.

\section{Experimental protocol in two separate groups}

Construction of models of bilateral pulmonary inhalation injury in dogs and administration of lung lavage. The experiments were performed on 19 hybrid male dogs from Chongqing, China, which were randomly divided into three groups: $A, B$ and $C(n=6,7$ and 6 , respectively). In six dogs from group A, positive end-expiratory pressure (PEEP) controlled respiration was conducted. In seven dogs from group B, PEEP was performed following injury; a left-lung lavage was conducted $1 \mathrm{~h}$ subsequent to injury and a right-lung lavage was conducted 30 min later. In six dogs from group C, a left-lung lavage was performed $1 \mathrm{~h}$ after injury and a right-lung lavage was conducted $4 \mathrm{~h}$ later. The experiment procedures were as follows: $12 \mathrm{~h}$ following food and water deprivation, an intramuscular injection of ketamine $(10 \mathrm{mg} / \mathrm{kg})$ and atropine $(0.3 \mathrm{mg})$ was administered to induce anesthesia in the dogs. A silicone tube (inner diameter, $2 \mathrm{~mm}$ ) was inserted into the left femoral artery to monitor the mean arterial pressure (MAP) continuously and to obtain arterial blood samples. In addition, a 5F Ganz-swan floating catheter (C.R.Bard, Inc., Murray Hill, NJ, USA) was inserted into the femoral vein to monitor the hemodynamic changes. Anesthesia was maintained by intravenous injection of amobarbital sodium $(10 \mathrm{mg} / \mathrm{kg} / \mathrm{h}$; Shanghai New Asia Pharmaceutical Co., Ltd., Shanghai, China) with the dose decreasing progressively. Tracheal intubation was applied for spontaneous breathing. After $1 \mathrm{~h}$, acute severe sawdust smoke inhalation injury was induced in the dogs. Following injury, mechanical ventilation with $40 \%$ oxygen was applied (respiration rate, 20 times/min, PEEP $5 \mathrm{mmHg}$ ) and the TV was adjusted in order to maintain $\mathrm{PetCO}_{2}$ at a level of $30 \mathrm{mmHg}$. During the experiment, dogs in each group were administered intravenous infusion of $5 \%$ dextrose in normal saline $(0.1 \mathrm{ml} / \mathrm{kg} / \mathrm{min})$. Subjects in group A were administered an extra infusion volume, which equaled the mean retention in the lungs in dogs of groups $\mathrm{B}$ and $\mathrm{C}$ following lung lavage.

Construction of models of single lung inhalation injury in dogs. The models were established using 19 hybrid male dogs from Chongqing, China, which were grouped randomly into group A1, B1 and C1. In seven dogs from group A1, tracheal intubation was conducted for spontaneous air breathing $24 \mathrm{~h}$ after smoke inhalation injury in the left lung. A small oxygen tube was inserted into the trachea $(10 \mathrm{~cm})$, and oxygen was supplied (3 1/min). For each of the six subjects in groups B1 and $\mathrm{Cl}$, high volume lavage (volume dose $250 \mathrm{ml}$ ) was performed on the injured lung $1 \mathrm{~h}$ after inhalation injury, followed by a simple vacuum aspiration. The lavage fluid used was normal saline complex solution in group B1, and perfluorodecalin in group $\mathrm{C} 1$. Perfluorodecalin was subpackaged in the $250-\mathrm{ml}$ glass. Prior to usage, it was sealed $15 \mathrm{~min}$ after being fully replaced with $\mathrm{O}_{2}(3 \mathrm{l} /$ min). Perfluorodecalin (F2 Chemicals Ltd., Lancashire, UK), is a perfluorinated liquid fluorocarbon product. It is colorless and tasteless, with a freezing point of $-50^{\circ} \mathrm{C}$ and a boiling point of $142^{\circ} \mathrm{C}$. It has a molecular weight of $462 \mathrm{Da}$, a specific weight of $1.917 \mathrm{~kg} / \mathrm{l}$, a metabolic viscosity of $3.25 \mathrm{~mm}^{2} / \mathrm{sec}$, a surface 
Table I. Changes of $\mathrm{PaO}_{2}$ and $\mathrm{SaCOHb}$ in the three groups.

\begin{tabular}{|c|c|c|c|c|c|c|c|}
\hline \multirow[b]{2}{*}{ Time course } & \multicolumn{3}{|c|}{$\mathrm{PaO}_{2}(\mathrm{mmHg})$} & \multirow[b]{2}{*}{$\mathrm{FIO}_{2}(\%)$} & \multicolumn{3}{|c|}{$\mathrm{SaCOHb}(\%)$} \\
\hline & Group A & Group B & Group C & & Group A & Group B & Group C \\
\hline Pre-injury & $176 \pm 18$ & $174 \pm 24 .$. & $183 \pm 22 \ldots$ & 40 & $3.5 \pm 0.39$ & $4.1 \pm 0.37$ & $4.0 \pm 0.38$ \\
\hline Left-lung lavage & $173 \pm 17$ & $218 \pm 20^{\mathrm{a}, \mathrm{b}}$ & $225 \pm 24^{\mathrm{a}, \mathrm{b}}$. & 100 & $30 \pm 3.1^{\mathrm{a}}$ & $22 \pm 1.9^{\mathrm{a}, \mathrm{b}}$ & $24 \pm 3.2^{\mathrm{a}}$ \\
\hline Right-lung lavage & $170 \pm 22$ & $165 \pm 24 .$. & $195 \pm 25^{\mathrm{a}-\mathrm{c}}$ & 100 & $22 \pm 2.1^{\mathrm{a}}$ & $13 \pm 2.0^{\mathrm{a}, \mathrm{b}}$ & $8.0 \pm 1.1^{\mathrm{a}-\mathrm{c}}$ \\
\hline $1 \mathrm{~h}$ post-lavage & $159 \pm 27^{a}$ & $102 \pm 16^{\mathrm{a}, \mathrm{b}}$ & $124 \pm 17^{\mathrm{a}-\mathrm{c}}$ & 40 & $16 \pm 1.7^{\mathrm{a}}$ & $11 \pm 0.9^{\mathrm{a}, \mathrm{b}}$ & $7.2 \pm 0.58^{\mathrm{a}-\mathrm{c}}$ \\
\hline $4 \mathrm{~h}$ post-lavage & $165 \pm 19$ & $129 \pm 16^{\mathrm{a}, \mathrm{b}}$ & $155 \pm 19^{a-c}$ & 40 & $11 \pm 1.3^{\mathrm{a}}$ & $8.6 \pm 0.74^{\mathrm{a}, \mathrm{b}}$ & $6.0 \pm 0.49^{\mathrm{a}, \mathrm{b}}$ \\
\hline
\end{tabular}

${ }^{\mathrm{a}} \mathrm{P}<0.05$, compared with pre-injury as determined by a two-tailed paired t-test. ${ }^{\mathrm{b}} \mathrm{P}<0.05$, compared with group $\mathrm{A}$. ${ }^{\mathrm{c}} \mathrm{P}<0.05$, compared with group B. Group A received no lavage following injury, group B received lavage for both lungs at 30-min intervals while group C received lavage for both lungs at 4-h intervals. $\mathrm{FiO}_{2}$ was kept at $40 \%$ during the study except for periods of lavage. $\mathrm{PAO}_{2}$, arterial blood partial pressure of oxygen; $\mathrm{SaCOHb}$, arterial blood carboxyhemoglobin saturation; $\mathrm{FIO}_{2}$, fraction of inspired oxygen.

tension of $5.10 \mathrm{mN} / \mathrm{m}$, an oxygen solubility of $24.4 \mathrm{ml} / 100 \mathrm{~g}$ and a $\mathrm{CO}_{2}$ solubility of $93 \mathrm{ml} / 100 \mathrm{~g}$.

Sample processing. The surgery time of lung-lavage and the intrapulmonary retention of lavage fluid was recorded following the vacuum aspiration.

The blood gas analysis and hemodynamic parameters, which were the partial pressure $(\mathrm{Pa})$ of oxygen and carbon dioxide in femoral arterial and mixed venous blood, were determined by the automatic blood gas system (AVL-990; AVL Medical Instruments, Basel, Switzerland). The heart rate (HR) and MAP in the dogs were monitored and recorded by the multi-function monitor (HP-66s; Hewlett-Packard, Palo Alto, CA, USA). The cardiac output (CO) was measured using a thermodilution method (8). Then the intrapulmonary shunt rate $\left(\mathrm{Q}_{\mathrm{S}} / \mathrm{Q}_{\mathrm{T}}\right.$; shunt quantity to total quantity) was calculated with the data obtained.

The arterial blood carboxyhemoglobin saturation $(\mathrm{SaCOHb})$ was measured using four-wavelength spectrophotometry (9).

Changes in pulmonary function, including peak airway pressure (Ppaw), mean airway pressure (Pm) and TV were monitored and recorded by the ventilator (NewPort-900C; Newport Medical Instruments, Inc.). Dynamic compliance (Cdyn) and the volume ratio of dead space to tidal space (Vd/Vt) were calculated with the data obtained and with the following equations: $\mathrm{Cdyn}=\mathrm{TV} / \mathrm{Pm}, \mathrm{Vd} / \mathrm{Vt}=\left(\mathrm{PaCO}_{2}-\mathrm{PetCO}_{2}\right) \times 100 \% /$ $\mathrm{PaCO}_{2}$.

Pathological changes in ex vivo organs involved sacrificing (by femoral artery exsanguination) the animals under anesthesia $24 \mathrm{~h}$ after injury. The two lungs were exposed to observe the general pathological changes. Small sections of tissues were obtained from the posterior sections of the left and right lungs and hematoxylin and eosin staining was performed following sectioning. Pathomorphological changes in the lung tissues were observed under a light microscope (37XB, Shanghai Optical Instrument Factory, Shanghai, China). The hepatic tissue water content was measured with the dry-weight method (10).

For the biochemical tests of blood plasma and lung homogenate, malondialdehyde (MDA) was determined with thiobarbituric acid; superoxide dismutase (SOD) was measured with xanthine oxidase; and total anti-oxidative activities were assessed with $\mathrm{Fe}^{3+}$ reduction $(\mathrm{OA}=\mathrm{MDA} / \mathrm{SOD})$. The reagent kits were provided by the Nanjing Jiancheng Bioengineering Institute (Nanjing, China). The lavage fluid was assessed for formaldehyde using the chromium-acid reaction and acetaldehyde using the iodoform reaction and the chloroform-extraction method.

Statistical analysis. Data are expressed as the mean \pm standard deviation. Global data was compared by analysis of variance. A two-tailed paired t-test was performed on the data within each group, and a non-paired t-test was performed on the corresponding data across the groups. $\mathrm{P}<0.05$ was considered to indicate a statistically significant difference.

\section{Results}

\section{Safety control of lung lavage}

General results. There was no difference in the dogs weight and the surgery time of a unilateral lung lavage across the three groups. In addition, no significant differences were noted in the unilateral lung lavage fluid retention following the vacuum aspiration.

Hemodynamic changes. HR and MAP decreased significantly as a result of inhalation injury. With time, HR and MAP did not present any marked fluctuation in groups A, B and C. MAP and HR remained stable during the lung-lavage. At the later stage of the experiment, MAP in group $\mathrm{C}$ was marginally higher compared with that in group A and B. No case of severe arrhythmia occurred in the dogs during the lavage period.

Changes in the pulmonary ventilation function. At the early period (within $\sim 2 \mathrm{~h}$, the period for bilateral lung lavage) following inhalation injury, $\mathrm{PaO}_{2}$ increased marginally for a short period and then reduced slowly in the dogs from group A. With the same fraction of inspired oxygen $\left(\mathrm{FiO}_{2}\right)$ value, $\mathrm{PaO}_{2}$ was markedly lower following lavage, compared with the value prior to injury. $\mathrm{PaO}_{2}$ in group $\mathrm{C}$ was higher compared with that in group $\mathrm{B}$ prior to, during and following the right-lung lavage. During lavage, the lowest level of $\mathrm{PaO}_{2}$ was $68 \mathrm{mmHg}$ $\left(\mathrm{FiO}_{2}=0.4\right)$, which occurred in one group $\mathrm{B} \operatorname{dog} 1 \mathrm{~h}$ after the right-lung lavage. The blood carbon monoxide emission was not effected during lavage: $\mathrm{SaCOHb}$ increased sharply by $>80 \%$ instantly following injury and then presented an 
Table II. Pulmonary function changes in three groups.

\begin{tabular}{|c|c|c|c|c|c|c|}
\hline \multirow[b]{2}{*}{ Time course } & \multicolumn{2}{|c|}{$\mathrm{Vd} / \mathrm{Vt}, \%$} & \multicolumn{2}{|c|}{$\mathrm{Cdyn}, \mathrm{ml} / \mathrm{cmH}_{2} \mathrm{O}$} & \multicolumn{2}{|c|}{$\mathrm{Q}_{\mathrm{S}} / \mathrm{Q}_{\mathrm{T}}, \%$} \\
\hline & Group A & Group B & Group A & Group B & Group A & Group B \\
\hline Pre-injury & $10 \pm 2.2$ & $12 \pm 2.5$ & $30.9 \pm 1.4$ & $31.2 \pm 1.6$ & $8.0 \pm 0.7$ & $8.8 \pm 0.7$ \\
\hline $4 \mathrm{~h}$ post-injury & $12 \pm 2.0$ & $12 \pm 3.3$ & $30.4 \pm 1.3$ & $29.2 \pm 1.5^{\mathrm{a}}$ & $6.2 \pm 1.0^{\mathrm{a}}$ & $11.5 \pm 1.3^{\mathrm{a}, \mathrm{b}}$ \\
\hline $8 \mathrm{~h}$ post-injury & $12 \pm 1.7$ & $11 \pm 2.1$ & $29.9 \pm 1.2^{\mathrm{a}}$ & $29.4 \pm 1.4^{\mathrm{a}}$ & $8.5 \pm 0.8$ & $10.4 \pm 1.1^{\mathrm{a}, \mathrm{b}}$ \\
\hline $12 \mathrm{~h}$ post-injury & $12 \pm 1.5$ & $9.5 \pm 1.3$ & $28.6 \pm 1.1^{\mathrm{a}}$ & $29.1 \pm 1.5^{\mathrm{a}}$ & $16.4 \pm 2.0^{\mathrm{a}}$ & $24.7 \pm 2.7^{\mathrm{a}, \mathrm{b}}$ \\
\hline $16 \mathrm{~h}$ post-injury & $10 \pm 0.8$ & $12 \pm 1.5$ & $27.8 \pm 1.2^{\mathrm{a}}$ & $27.6 \pm 1.1^{\mathrm{a}}$ & $20.6 \pm 1.8^{\mathrm{a}}$ & $24.8 \pm 2.1^{\mathrm{a}, \mathrm{b}}$ \\
\hline $20 \mathrm{~h}$ post-injury & $9.6 \pm 1.1$ & $11 \pm 1.0$ & $27.8 \pm 1.4^{\mathrm{a}}$ & $27.1 \pm 1.3^{\mathrm{a}}$ & $20.1 \pm 2.1^{\mathrm{a}}$ & $22.9 \pm 2.2^{\mathrm{a}, \mathrm{b}}$ \\
\hline $24 \mathrm{~h}$ post-injury & $13 \pm 1.3^{\mathrm{a}}$ & $11 \pm 1.6$ & $27.5 \pm 1.1^{\mathrm{a}}$ & $28.3 \pm 1.4^{\mathrm{a}}$ & $21.9 \pm 2.7^{\mathrm{a}}$ & $24.7 \pm 2.5^{\mathrm{a}, \mathrm{b}}$ \\
\hline
\end{tabular}

${ }^{\mathrm{a}} \mathrm{P}<0.05$ vs. pre-injury as determined by a two-tailed paired t-test. ${ }^{\mathrm{b}} \mathrm{P}<0.05$ vs. group A. Group A received no lavage following injury but group B received lavage for both lungs at 30-min intervals, therefore a non-paired t-test was used. Vd/Vt,volume ratio of physiological dead space to tidal space volume of ventilation; Cdyn, dynamic compliance; $\mathrm{Q}_{\mathrm{S}} / \mathrm{Q}_{\mathrm{T}}$, ratio of pulmonary capillary blood flow without oxygenation to cardiac output (quantity ratio of shunt to total).

exponential decrease throughout the course of the experiment. However, in dogs from group B and C, SaCOHb decreased at a marginally higher rate, stemming from hyperventilation during lavage, as shown in Table I.

\section{Short-term effects of lung lavage}

Pulmonary function changes in dogs from group $A$ at $24 \mathrm{~h}$. There was a small increase in Ppaw in group A $12 \mathrm{~h}$ after the inhalation injury. However, in group B, it increased significantly following the application of high volume lung lavage, and essentially remained at a level that was marginally higher than that of group A at $4 \mathrm{~h}$ after injury. However, the Cdyn change trend showed the opposite results. Vd/Vt, exhibited a small change in all the three groups throughout the duration of the study and was not evidently influenced by the injury or the lung lavage, which was completely different from the change of $\mathrm{Q}_{\mathrm{S}} / \mathrm{Q}_{\mathrm{T}}$ (Table II). $\mathrm{PaO}_{2}$ decreased progressively in dogs from group A following injury. In group B, $\mathrm{PaO}_{2}$ decreased notably for a short period subsequent to lung lavage and returned to a level close to that of group A at $8 \mathrm{~h}$ after injury, yet did not reach the level of group A at $24 \mathrm{~h}$ after injury (Fig. 1).

Pathological changes in organs and tissues in dogs $24 \mathrm{~h}$ after injury in the first set of experiments. In dogs from group A and B, both lungs exhibited severe edema and mostly resembled liver at $24 \mathrm{~h}$ after injury. After the hilar bronchus was cut open, the majority of the mucous membrane was observed to be shed off in the form of strips. Severe submucosal hyperemia and edema existed, with extensive punctate hemorrhage, and a great quantity of pink foam-like liquid on the surface of mucosa. The severity of the bipulmonary pathological changes between group A was marginally lower compared with dogs from group B. A large number of mucopurulent emboli and ablated necrotic mucous membranes were observed under light microscopy in the bronchioles of dogs from group A and inflammatory infiltration existed widely in the lung parenchyma. 'Edema sets' and 'inflammatory sets' were formed around the bronchioles, accompanying small arteries and interlobular veins, containing uniformly-stained

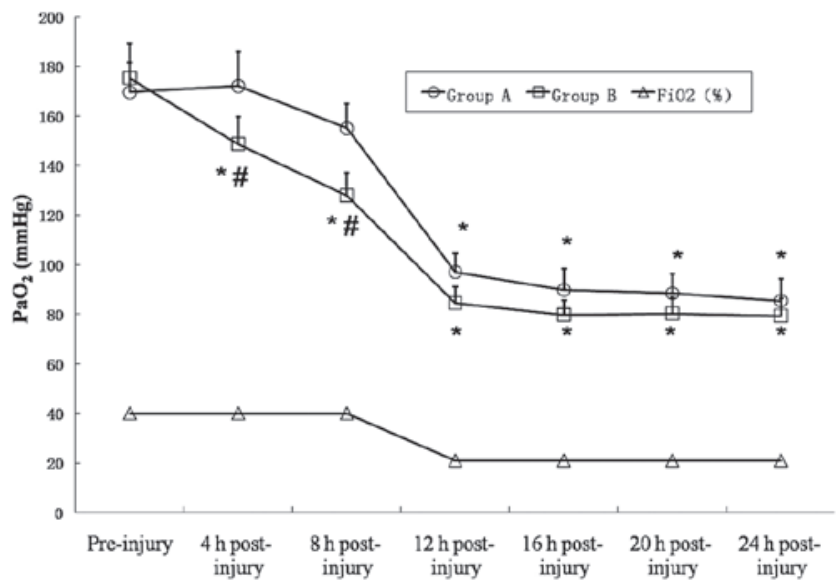

Figure 1. Changes of $\mathrm{PaO}_{2}$ at $24 \mathrm{~h}$ after injury. ${ }^{*} \mathrm{P}<0.05$ vs. pre-injury, as determined by a two-tailed paired t-test. ${ }^{\#} \mathrm{P}<0.05$ vs. group A. Group A received no lavage following injury but group $\mathrm{B}$ received lavage for both lungs at 30-min intervals, non-paired t-test. $\mathrm{PaO}_{2}$, partial pressure of oxygen.

proteinaceous exudates, as shown in Fig. 2. In dogs from group B, the damage to the pulmonary alveolus structure appeared to be lighter with fewer incidences of mucopurulent emboli and necrotic mucous membrane within the bronchioles.

Assessment of the lavage fluid following lung lavage in the second section of the experiments. The solute concentration, formaldehyde and acetaldehyde concentration, and the total content of solute of the left-lung lavage fluid in group B1 were notably higher compared with those of group $\mathrm{C} 1$ (perfluorodecalin lavage), as observed in Fig. 3.

Changes of pulmonary function in dogs in the second set of experiments. The automatic breathing frequency in all three groups of dogs increased notably, immediately following injury and then decreased 12-24 h in group B1 dogs, remaining significantly higher compared with that in group $\mathrm{C} 1 \mathrm{dogs}$. In contrast to the dogs under controlled respiration, $\mathrm{PaO}_{2}$ generally decreased with spontaneous breathing at the early stage after the inhalation injury in the dogs and then was generally maintained at $\sim 70 \mathrm{mmHg}$. $\mathrm{PaO}_{2}$ decreased again notably $20 \mathrm{~h}$ 


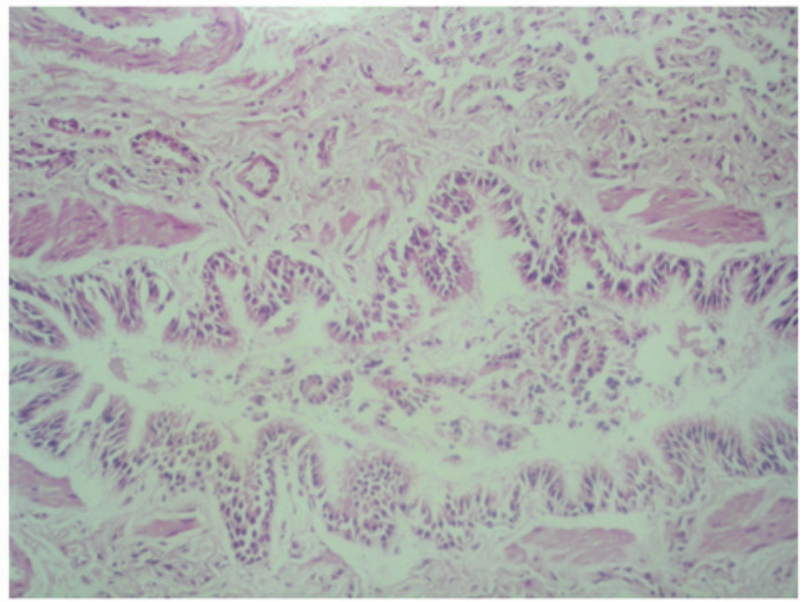

Figure 2. The light microscopic manifestations of the lung tissues in group A (injury, without lavage) $24 \mathrm{~h}$ after injury. Mucopurulent bolt and shedding necrotic mucosa stored in bronchiole cavity. Numerous inflammatory cells infiltrated the lung parenchyma. 'Edema set' with red staining proteinaceous exudates inside could be seen around the accompanied small arteries. Stain, hematoxylin and eosin; magnification, x100.

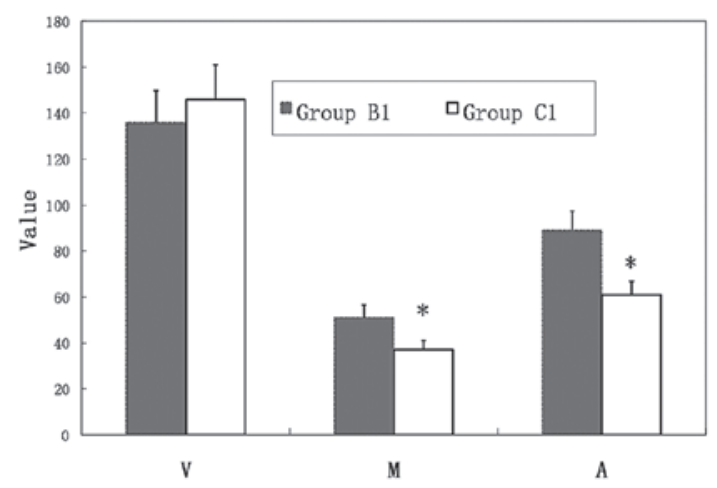

Figure 3. Changes of certain indicators of lavage eluate in three groups $\mathrm{V}$, eluate volume (ml); M, formaldehyde concentration (mg/l); A, acetaldehyde concentration $(\mathrm{mg} / \mathrm{l})$. ${ }^{*} \mathrm{P}<0.05$ vs. group $\mathrm{B} 1$ as determined by a non-paired t-test.

after injury. In group $\mathrm{B} 1$ dogs, $\mathrm{PaO}_{2}$ decreased significantly immediately following left-lung lavage and rebounded to the level of the non-lavage dogs $6 \mathrm{~h}$ later. The mean $\mathrm{PaO}_{2}$ was marginally higher compared with that of the non-lavage dogs 20-24 h after injury. In dogs from group $\mathrm{C} 1, \mathrm{PaO}_{2}$ was marginally reduced after the lung lavage, but had been notably higher compared with the values in group A1 and B1 since $12 \mathrm{~h}$ after injury (Fig. 4).

Ex vivo pulmonary pathological and pathophysiological changes in dogs in the second set of experiments. Generally, the left lungs in all dogs in the three groups exhibited severe edema $24 \mathrm{~h}$ after smoke inhalation injury. Although edema existed in the right lungs, the extent of the damage was light and complete wet change of the lungs was rare, which demonstrated that the right and left lungs in dogs were separated effectively during smoke inhalation. Subsequent to the hilar bronchus being cut open, the left bronchial mucous membrane was observed to be shed off in the form of streaks. Submucosal hyperemia and edema were noted, with extensive punctate hemorrhage. In dogs of groups A1 and B1, a great quantity

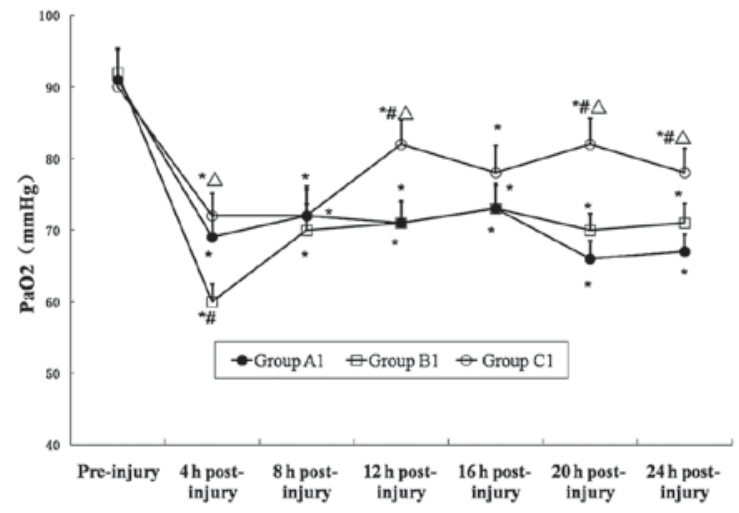

Figure 4. Changes of $\mathrm{PaO}_{2}$ in three groups. ${ }^{*} \mathrm{P}<0.05$ vs. pre-injury, ${ }^{\#} \mathrm{P}<0.05$ vs. group $\mathrm{A} 1$ and ${ }^{\triangle} \mathrm{P}<0.05$ vs. group $\mathrm{B} 1$ as determined by a non-paired t-test. Group A1, dogs with spontaneous breathing but no lavage following injury in the left lung. Group B1, dogs with normal saline complex solution lavage on the injured lung. Group $\mathrm{C} 1$, dogs with perfluorodecalin lavage on the injured lung. $\mathrm{PaO}_{2}$, partial pressure of oxygen.

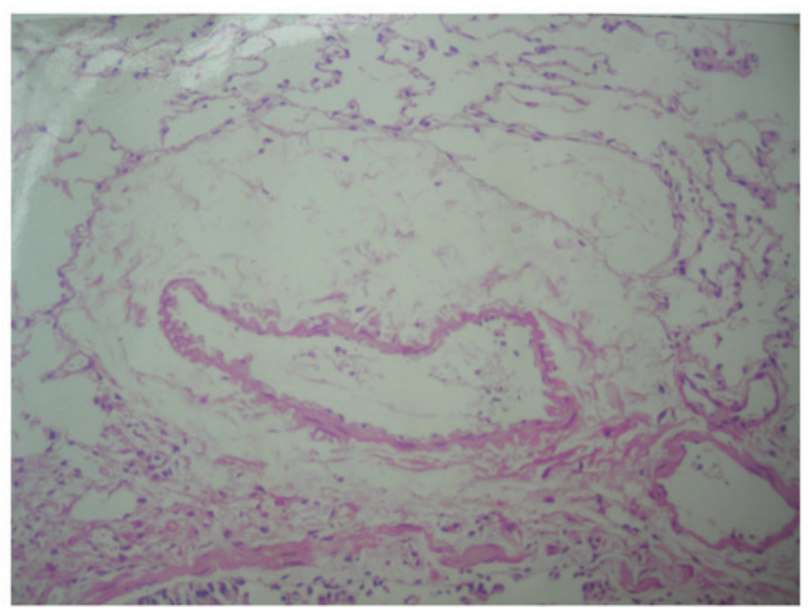

Figure 5. The light microscopic manifestations of the left lung in group A1 (left lung injury without lavage) at $24 \mathrm{~h}$ after injury showed mucopurulent bolt and shedding pseudomembrane in bronchiole cavity, a large quantity of inflammatory cell infiltration in the lung parenchyma and marked appearance of 'edema sets' around the capillaries. Stain, hematoxylin and eosin; magnification, x100.

of pink foam-like liquid was stored within the left bronchus, while in group $\mathrm{C} 1 \mathrm{dogs}$, stored liquid was also observed but with rare pink foam. The right bronchial mucous membrane exhibited marginal hyperemia and edema. No small petechial hemorrhage was observed.

In all three groups of dogs, eosinophilic proteinaceous exudate was observed in the pulmonary alveoli of the left lung under the light microscope. In group A1, a large quantity of mucopurulent emboli and ablated pseudomembranes were observed in the bronchioles, and inflammatory infiltration was found in the lung parenchyma. The consistency of the pulmonary alveolus structure was damaged, 'edema sets' formed around the bronchioles, accompanying small arteries and interlobular veins (Fig. 5). In dogs from group B1, the consistency of the pulmonary alveolus structure was only marginally disrupted, with little intra-alveolar proteinaceous exudate. In the dogs from group $\mathrm{C} 1$, the capillary structure was basically normal, without an evident 'edema set' being observed. 


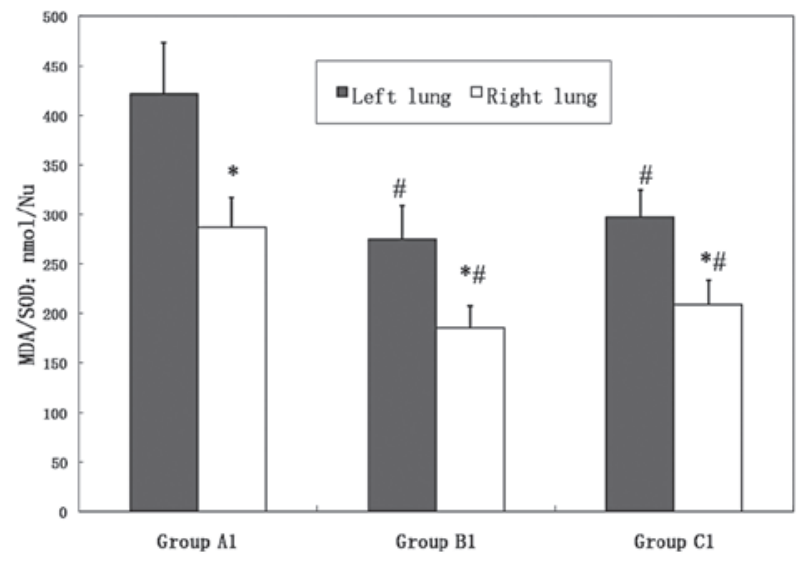

Figure 6. Changes of the oxidation capacity of the posterior right lung in three groups of dogs $24 \mathrm{~h}$ after injury. ${ }^{*} \mathrm{P}<0.05$ vs. the left posterior lobe in the same group as determined by a two-tailed paired t-test. ${ }^{\#} \mathrm{P}<0.05$ vs. the same lobe in group A1, as determined by a non-paired t-test.

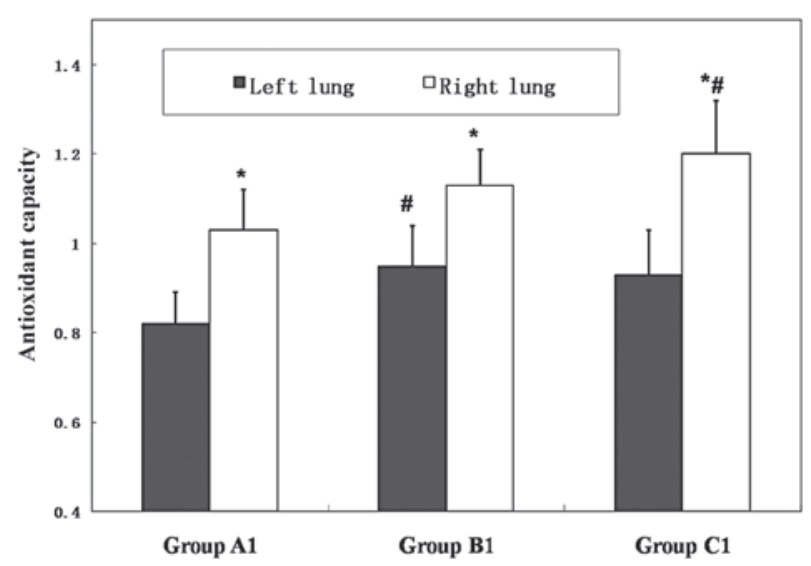

Figure 7. Changes of the anti-oxidant capacity ( $\mu / \mathrm{mg}$ pro.) of the posterior right lung in three groups of dogs $24 \mathrm{~h}$ after injury. ${ }^{*} \mathrm{P}<0.05$ vs. the left posterior lobe in the same group as determined by a two-tailed paired t-test. ${ }^{\#} \mathrm{P}<0.05$ vs. the same lobe in group $\mathrm{A} 1$, as determined by a non-paired t-test.

In the non-injured lung, (the right lung) in all three groups, the intra-alveolar proteinaceous exudate was not observed and mucopurulent emboli were scarcely identified in the bronchiole cavity. Without an ablated pseudomembrane, the pulmonary alveolus structure remained intact. In group A1, a thin 'edema set' appeared around the bronchioles, accompanying small arteries and interlobular veins; while in the dogs from group B1 and C1 dogs, the bronchiolar and capillary structure remained generally normal.

Biochemical analysis of blood plasma and lung homogenate in dogs in the second part of experiments. In group B1 and C1 dogs, the MDA/SOD value in the bilateral pulmonary tissues remained notably lower compared with that in group A1 dogs $24 \mathrm{~h}$ after injury (Fig. 6). The oxidation capacity of the posterior right lung was evidently lower compared with that of the posterior left lung in all three groups. While the anti-oxidant capacity of group B1 and $\mathrm{C} 1$ was markedly higher compared with that of group A1, the anti-oxidant capacity of the posterior right lung was remarkably higher compared with that of the posterior left lung in each group (Fig. 7).

\section{Discussion}

The major causative factor of inhalation injury is smoke, rather than heat. A large number of toxic substances, produced by imperfect combustion of materials, coat the carbon particles, which are then inhaled resulting in entry to the lower respiratory tract or pulmonary alveoli leading to chemical lesion intoxication $(11,12)$. We hypothesized that we could eliminate the harmful dust and inflammatory exudates by lung lavage to relieve the primary injuries and secondary inflammatory reactions in the early stage of inhalation injury. However, in clinical practice, the lung water retention induced by lavage would intensify the general hypoxia $(13,14)$.

The present study demonstrates that neither of the two techniques of early high volume lung lavage for severe smoke inhalation injury in large animals, introduced in this study, induce intense fluctuation in the circulation system. Lung lavage does not interfere in the blood carbon monoxide emission. Although it may disrupt the pulmonary gas exchange functions for a short period, the damage was recovered to a great extent $4 \mathrm{~h}$ following lavage. The ventilation disorder during lavage can also be avoided by administration of a high concentration of oxygen. In addition, a longer interval between the lavage in the two different lungs is likely to be safer in practice.

The results of the present study reveal that following the two-lung inhalation injury in dogs, no improvement in the pulmonary function was observed within $24 \mathrm{~h}$ of the normal saline complex solution lavage, manifested by the fact that the $\mathrm{PaO}_{2}$ level after lavage was lower compared with that in the non-lavage dogs. The Ppaw increased, yet the reduction of the pulmonary dynamic compliance, calculated with the Pm, was not prominent. Such a result indicates that the controlled air flow has to overcome a valve-like resistance when flowing into the lung, then pulmonary alveoli expanded rapidly and Pm dropped instantly. This process is likely to shorten the residence time of fresh air in pulmonary alveoli and thus reduce the pulmonary function of gas exchange. The fact that the intrapulmonary shunt rate increased markedly but $\mathrm{Vd} / \mathrm{Vt}$ did not exhibit a great change in the lavaged-dogs indicates that alveolar water is the major factor that influences gas exchange. Compared with the non-lavaged dogs in group A1, normal saline complex solution-lavaged dogs in group B1 and perfluorodecalin lung-lavaged dogs in group $\mathrm{C} 1$ demonstrated a lower oxidant capacity and higher anti-oxidant capacity of the pulmonary tissues, these changes demonstrate that lung lavage could reduce secondary local and general inflammatory reactions following inhalation injury. Pathological section tests revealed that the pathological changes in the lavaged-dogs were only marginally improved compared with those of the non-lavaged dogs, which indicates that lung-lavage could only mitigate a type I cell damage response to a limited extent.

In the recovery process from the inhalation injury, due to the long course of disease, the poor general physical condition and interference of frequent pulmonary infection complications, it is extremely difficult to evaluate the long-term effect of a certain therapeutic measure. Additionally, a large sample size is required. Following bilateral lung lavage with normal saline complex solution, the fact that patients had lung water retention coexisted with the fact that inflammatory reactions 
in the blood plasma and tissues were relieved $(15,16)$. The extent to which they influence the pulmonary functions and the manner by which the overall currative effects of early high volume lung lavage in treating inhalation injury can be enhanced are questions that remain to be answered. In order to determine answers to these questions, models of acute severe unilateral pulmonary smoke inhalation injury in dogs were constructed and the high volume lavage with normal saline complex solution on the injured lung was performed $1 \mathrm{~h}$ after injury. Perfluorodecalin was also used in the lung lavage as the control. The results verified the effectiveness of the two-lung separation approach. The unilateral-lung severe smoke inhalation injury did result in secondary damage to the contralateral lung in dogs, but the primary and secondary injuries were prominently different in their severity. Pathological changes indicate that lung lavage with normal saline complex solution and perfluorodecalin is able to clean the lower respiratory tract effectively, and that lung lavage can mitigate the primary and secondary structural changes in pulmonary tissues to a certain degree. Perfluorodecalin lung lavage did not achieve the same results in cleansing as the normal saline complex solution, but a better short-term overall outcome was obtained in the perfluorodecalin-lavaged dogs compared with the normal saline-lavaged dogs and in the dogs which underwent natural development following injury. The major mechanism of the short-term effect of perfluorodecalin-lavage, i.e., improving respiratory function, may lie in its pulmonary cleansing function, gas exchange capacity, and the partial liquid ventilation function of the intrapulmonary perfluorodecalin retention $(17,18)$.

The present study aimed to investigate the high volume airway (particularly the small airway) lavage and alveolar wash at the early stage following inhalation injury, instead of the low-volume normal saline airway lavage at the middle and late period subsequent to injury, in their functions of eliminating the primary and early secondary injury factors following smoke inhalation, and alleviating the pulmonary lesions and the following pulmonary function impairment. At the early period of inhalation injury, the sodium and water transport function of the alveolar epithelium is not seriously damaged, therefore the intrapulmonary retention of water can be automatically eliminated, thereby avoiding aggravation of the pulmonary function impairment at the peak of the pulmonary edema $(19,20)$.

In the experimental design, particular attention was paid to the safety control in the lavage procedures, bearing the principle of exploring a method that is clinically applicable and favorable to the comprehensive treatment of the disease. The final unilateral water retention subsequent to lavage was 80-130 $\mathrm{ml}$ (retrieval rate 48-68\%). Repeated and excessive aspiration can markedly reduce the retention in the lung, but it is likely to aggravate hyperemia and hemorrhage in carina and bronchial mucosa. Therefore the pathological examination revealed that pulmonary hemorrhage declined as the vacuum aspiration increased in intensiveness $12-24 \mathrm{~h}$ after injury. In revising the technique details in the experiment, the following experiences in ensuring the safety during lung lavage were concluded. i) During the affusion and aspiration process with the bronchofiberscope, continuous oxygen-jet ventilation via the main bronchus should be adopted. The position of the slim breathing tube aperture has a great influence on oxygenation effects during lavage. The optimal position is $\sim 1 \mathrm{~cm}$ above the carina. ii) During aspiration, the lens end of the bronchofiberscope is limited to the lobar bronchus opening. The suction socket should not touch the bronchial wall. iii) A high retention retrieval rate should not be the only pursuit. Such a high volume lung lavage is easy to conduct and suitable for inhalation injury in dogs. With proper supporting measurements, an early high volume lung lavage does not exacerbate general hypoxia in dogs and only exhibits a marginal effect on the hemodynamic stability. Therefore, it is applicable to clinical patients.

$\mathrm{Q}_{\mathrm{S}} / \mathrm{Q}_{\mathrm{T}}$ reflects the ratio of pulmonary capillary blood flow without oxygenation to cardiac output. $\mathrm{Vd} / \mathrm{Vt}$ is the ratio of physiological dead space volume to tidal volume of ventilation. After the early high volume normal saline complex solution lung lavage was performed on the inhalation-injured dogs, the changes of $\mathrm{Q}_{\mathrm{S}} / \mathrm{Q}_{\mathrm{T}}$ and $\mathrm{Vd} / \mathrm{Vt}$ first observed in the present study were the following: $\mathrm{Q}_{S} / \mathrm{Q}_{\mathrm{T}}$ increased markedly while $\mathrm{Vd} / \mathrm{Vt}$ did not exhibit much change. Such changes may be attributed to the fact that pulmonary ventilation function damage is mainly caused by the increase in the number of pulmonary alveoli without ventilation or the rise of blood flow flowing directly from the pulmonary artery into left atrium without undergoing gas exchange. While alveolar dead space-like ventilation resulted from the abnormal distribution of pulmonary blood in pulmonary tissues, it is not the cause of pulmonary function damage. This phenomenon and its formation mechanism appear to fit well with the pathological influence of inhalation injury and lung lavage (21). The direct result of intra-alveolar retention of lavage fluid and the compression on the small airway by small airway mucosal edema and pulmonary interstitial edema is alveolar hypoventilation in a considerable portion of pulmonary alveoli. However, the retention of lavage fluid does not exert much influence on local blood flow distribution (22).

$\mathrm{PaO}_{2}$ is a significant clinical index which reflects the curative effect of pulmonary injuries. In the second set of experiments, $\mathrm{PaO}_{2}$ in the normal saline complex solution lavage group (group B1) was lower compared with that in the non-lavage group at the early period after lavage (which was the comprehensive result of lavage fluid retention in the left lung and mitigation of injuries in the right lung), but increased gradually with absorption of the fluid retention in the left lung. At $24 \mathrm{~h}$ after injury, $\mathrm{PaO}_{2}$ was already higher compared with that of non-lavage group (group A1), and the two-lung ventilation had also been improved as shown in Figs. 3 and 4. This outcome demonstrates that secondary lesions in the right lung in the lavage-group were minor compared with those in the non-lavage group. In group $\mathrm{C} 1$ dogs that underwent perfluorodecalin lung lavage, $\mathrm{PaO}_{2}$ decreased marginally at the early period following lavage, but increased gradually with the absorption of perfluorodecalin in the left lung and due to the therapeutic effect. $\mathrm{PaO}_{2}$ in this group was significantly higher compared with those in the other two groups 12-24 h after injury, which indicates the superiority of perfluorodecalin in lung lavage.

The cleansing effect of perfluorodecalin is not as efficient as that of the normal saline complex solution, which may be associated with their different physical characteristics. Normal 
saline complex solution is a water solution and during lavage, it produces an effect of a mechanical wash and rinse; in addition, it can mix with bronchial surface and alveolar fluids, dilute the solute components and then be partially aspirated. Repeated lavage and aspiration can result in an exponential replacement of solution, therefore achieving a strong cleansing effect. However, perfluorodecalin is a liquid that is insoluble in water and lipids. In the process of perfluorodecalin lavage, in addition to its effect of mechanical washing and rinsing, it may be that only the buoyancy force is involved in the clearance of intra-pulmonary fluid and solutes, as perfluorodecalin has a greater specific gravity. Thus, it is understandable that its cleansing effect is not as strong as that of normal saline complex solution $(18,19)$. The experiment results indicate that perfluorodecalin lung lavage can notably reduce airway pressure and escalate arterial partial pressure of oxygen, and thereby has a good short-term curative effect, despite the fact that it washes out less solutes. Prior to lavage, perfluorodecalin was sufficiently exchanged with pure oxygen in vitro. During lavage, oxygen jet ventilation supplementation was applied, which enabled the $\mathrm{PaO}_{2}$ level to remain at $>200 \mathrm{mmHg}$ throughout the duration of the lavage. The results indicated that the safety for dogs survival was ensured and thus suggested that the lung lavage method could be successful.

The present study demonstrated that early stage inhalation injury was indicated to be an appropriate time for lung lavage procedures to be conducted. The more severe the inhalation injury is, the more suitable it is to apply early lung lavage, which should be performed prior to or at the early period of pulmonary edema as at the middle and late period following inhalation injury ( $24 \mathrm{~h}$ after injury), there is a relatively strong bleeding tendency when necrotic mucosa is shed from the bronchi. Therefore, the problem of hemorrhage provoked by the repeated insertion of the bronchofiberscope into and out of the respiratory tract and by vacuum aspiration must be tackled during and after the period when the pulmonary edema subsided $(25,26)$. When adopting the lung lavage approach introduced in this study, the cardiovascular system remained stable during lavage. Furthermore, solid organ disfunction and skin burns could not significantly affect the safety of lung lavage practice. When $\mathrm{PaO}_{2}$ drops to $<200 \mathrm{mmHg}$ (at the peak of pulmonary edema and with controlled respiration of pure oxygen), and in the case of severe systemic failure, lung lavage may lead to irreversible general hypoxia. Thus those conditions should not be treated by lung lavage $(27,28)$. In lung lavage surgery, certain details require improvement. For instance, slimmer bronchofiberscopes with smoother surfaces are more favorable for enhancing the lavage-fluid-retrieval rate without aggravating hemorrhage. Following lung lavage surgery, effective cough irritation may possibly improve the pulmonary function of gas exchange $(29,30)$.

In conclusion, the approach introduced in the present study of early high volume lung lavage following severe inhalation injury could maintain the hemodynamics and pulmonary oxygenation stably and thus ensure dog survival during the procedure. The high volume lung lavage does not affect the emission of blood carbon monoxide. Normal saline complex solution lung lavage could cause short-term damage to the pulmonary ventilation function, but oxygen-jet ventilation during lavage and a PEEP ventilation with $40 \%$ oxygen during the non-lavage period ensured oxygen supply to the experimental animals. A longer interval between the lavage of two lungs is likely to be a safer practice compared with consecutive lavage of two lungs in dogs.

Early high volume lung lavage can markedly mitigate primary injury and secondary local and general inflammatory reactions in dogs with smoke inhalation injury.

Perfluorodecalin lung lavage may not achieve the same effect in clearing the lungs as the normal saline, but a greater short-term overall outcome was obtained in the perfluorodecalin-lavage- compared with the normal-saline complex solution-treated dogs and also in the dogs receiving no lavage subsequent to smoke inhalation injury.

\section{Acknowledgements}

The authors would like to thank Professor Min Bi, Anesthesiology Department, Southwest Hospital, who has aided in improving the technical details of the experiment. The present study was supported by a grant from the National Natural Science Foundation of China (grant no. NSFC-30772077).

\section{References}

1. Irrazabal CL, Capdevila AA, Revich L, Del Bosco CG, Luna CM Vujacich P, Villa R and Jorge MA: Early and late complications among 15 victims exposed to indoor fire and smoke inhalation. Burns 34: 533-538, 2008.

2. Mosier MJ, Pham TN, Park DR, Simmons J, Klein MB and Gibran NS: Predictive value of bronchoscopy in assessing the severity of inhalation injury. J Burn Care Res 33: 65-73, 2012.

3. Lawson-Smith P, Jansen EC, Hilsted L and Hyldegaard O: Effect of hyperbaric oxygen therapy on whole blood cyanide concentrations in carbon monoxide intoxicated patients from fire accidents. Scand J Trauma Resusc Emerg Med 18: 32, 2010.

4. Baldi MM, Nair J, Athavale A, Gavali V, Sarkar M, Divate S and Shah U: Serial lobar lung lavage in pulmonary alveolar proteinosis. J Bronchology Interv Pulmonol 20: 333-337, 2013.

5. Albright JM, Romero J, Saini V, Sixt SU, Bird MD, Kovacs EJ, Gamelli RL, Peters J and Majetschak M: Proteasomes in human bronchoalveolar lavage fluid after burn and inhalation injury. J Burn Care Res 30: 948-956, 2009.

6. Wuyts WA, Dooms C and Verleden GM: The clinical utility of bronchoalveolar lavage cellular analysis in interstitial lung disease. Am J Respir Crit Care Med 187: 777, 2013.

7. Heimbach DM and Waeckerle JF: Inhalation injures. Ann Emery Med 17: 1316-1320, 1988.

8. Ameloot K, Van De Vijver K, Broch O, Van Regenmortel N, De Laet I, Schoonheydt K, Dits H, Bein B and Malbrain ML: Nexfin Noninvasive Continuous Hemodynamic Monitoring: Validation against Continuous Pulse Contour and Intermittent Transpulmonary Thermodilution Derived Cardiac Output in Critically Ill Patients. ScientificWorldJournal 2013: 519080, 2013.

9. Myers DE, Anderson LD, Seifert RP, Ortner JP, Cooper CE, Beilman GJ and Mowlem JD: Noninvasive method for measuring local hemoglobin oxygen saturation in tissue using wide gap second derivative near-infrared spectroscopy. J Biomed Opt 10: 034017, 2013.

10. Moeini M,Nematbakhsh M,Fazilati M, Talebi A,Pilehvarian AA, Azarkish F, Eshraghi-Jazi F and Pezeshki Z: Protective role of recombinant human erythropoietin in kidney and lung injury following renal bilateral ischemia-reperfusion in rat model. Int $\mathbf{J}$ Prev Med 4: 648-655, 2013.

11. Toon MH, Maybauer MO, Greenwood JE, Maybauer DM and Fraser JF: Management of acute smoke inhalation injury. Crit Care Resusc 12: 53-61, 2010.

12. Fuchs PC, Demir E, Reuber K, Stromps P, Wolter T and Pallua N: Intra-alveolar IL-6 levels following burn and inhalation injury. Burns 35: 840-844, 2009. 
13. Pollock K, Albares L, Wendt $\mathrm{C}$ and Hubel A: Isolation of fibroblasts and epithelial cells in bronchoalveolar lavage (BAL). Exp Lung Res 39: 146-154, 2013.

14. Rabello E, Batista VF, Lago PM, Alvares Rde A, Martinusso Cde A and Lapa e Silva JR: Bronchoalveolar lavage analysis in victims of severe facial burns. J Bras Pneumol 35: 343-350, 2009 (In English and Portuguese).

15. Jacob S, Kraft R, Zhu Y, Jacob RK, Herndon DN, Traber DL, Hawkins HK and Cox RA: Acute secretory cell toxicity and epithelial exfoliation after smoke inhalation injury in sheep: an electron and light microscopic study. Toxicol Mech Methods 20: 504-509, 2010.

16. Chacko J, Jahan N, Brar G and Moorthy R: Isolated inhalational injury: clinical course and outcomes in a multidisciplinary intensive care unit. Indian J Crit Care Med 16: 93-99, 2012

17. Murgia X, Mielgo V, Valls-i-Soler A, Ruiz-del-Yerro E and Rey-Santano C: Aerosolized perfluorocarbon improves gas exchange and pulmonary mechanics in preterm lambs with severe respiratory distress syndrome. Pediatr Res 72: 393-399, 2012.

18. Romano MR, Vallejo-Garcia JL, Parmeggiani F, Vito R and Vinciguerra P: Interaction between perfluorcarbon liquid and heavy silicone oil: risk factor for 'sticky oil' formation. Curr Eye Res 37: 563-566, 2012.

19. van Helden HP, van de Meent D, Oostdijk JP, Joosen MJ, van Esch JH, Hammer AH and Diemel RV: Protection of rats against perfluoroisobutene (PFIB)-induced pulmonary edema by curosurf and N-acetylcysteine. Inhal Toxicol 16: 549-564, 2004.

20. Asmussen S, Maybauer DM, Fraser JF, Jennings K, George S, Keiralla A and Maybauer MO: Extracorporeal membrane oxygenation in burn and smoke inhalation injury. Burns 39: 429-435, 2013.

21. Woods KS, Defarges AM, Abrams-Ogg AC, Dobson H, Viel L, Brisson BA and Bienzle D: Comparison between manual aspiration via polyethylene tubing and aspiration via a suction pump with a suction trap connection for performing bronchoalveolar lavage in healthy dogs. Am J Vet Res 74: 523-529, 2013.
22. Badiozaman R, Tahereh P, Shideh D, Mohammadreza B, Ahmadreza A and Seyyedahmad T: Whole lung lavage of nine children with pulmonary alveolar proteinosis: experience in a tertiary lung center. Iran J Pediatr 23: 95-99, 2013.

23. Von der Hardt K, Kandler MA, Brenn G, Scheuerer K, Schoof E, Ditsch J and Rascher W: Comparison of aerosol therapy with different perfluorocarbons in surfactant-depleted animals. Crit Care Med 32: 1200-1206, 2004.

24. Willems S, Verleden SE, Vanaudenaerde BM, Wynants M, Dooms C, Yserbyt J, Somers J, Verbeken EK, Verleden GM and Wuyts WA: Multiplex protein profiling of bronchoalveolar lavage in idiopathic pulmonary fibrosis and hypersensitivity pneumonitis. Ann Thorac Med 8: 38-45, 2013.

25. Lange M, Hamahata A, Traber DL, Connelly R, Nakano Y, Traber LD, Schmalstieg FC, Herndon DN and Enkhbaatar P: Pulmonary microvascular hyperpermeability and expression of vascular endothelial growth factor in smoke inhalation- and pneumonia-induced acute lung injury. Burns 38: 1072-1078, 2012.

26. Cancio LC: Airway management and smoke inhalation injury in the burn patient. Clin Plast Surg 36: 555-567, 2009.

27. Henderson RF: Use of bronchoalveolar lavage to detect respiratory tract toxicity of inhaled material. Exp Toxicol Pathol 57 (Suppl 1): 155-159, 2005.

28. Albright JM, Davis CS, Bird MD, Ramirez L, Kim H, Burnham EL, Gamelli RL and Kovacs EJ: The acute pulmonary inflammatory response to the graded severity of smoke inhalation injury. Crit Care Med 40: 1113-1121, 2012.

29. Starnes-Roubaud M, Bales EA, Williams-Resnick A, Lumb PD, Escudero JA, Chan LS and Garner WL: High frequency percussive ventilation and low $\mathrm{FiO}(2)$. Burns 38: 984-991, 2012.

30. Fracasso T and Schmeling A: Delayed asphyxia due to inhalation injury. Int J Legal Med 125: 289-292, 2011. 